\title{
Supraspinatus Muscle
}

National Cancer Institute

\section{Source}

National Cancer Institute. Supraspinatus Muscle. NCI Thesaurus. Code C33709.

One of four rotator cuff muscles that form a musculotendinous cuff around the glenohumeral joint, which provides muscular support to the shoulder. It arises from the supraspinous fossa of the scapula, inserts into the greater tubercle of the humerus, and assists to abduct the arm. 